\title{
Nutrition, physical activity and health status in Europe: an overview
}

\author{
Michael J. Gibney \\ Department of Clinical Medicine and Institute of European Food Studies, The Trinity Centre for Health Sciences, \\ St. James' Hospital, IRL- Dublin 8, Ireland
}

Accepted: 23 June 1999

\begin{abstract}
Introduction: The European diet is characterized by a wide variation in every aspect of eating from the timing of meals to the composition of meals. In general, there is a tendency in terms of dietary advice towards lower fat intakes in order to reduce saturated fatty acid intake and to reduce the risk of obesity. Such diets are most successful and yield the most favourable metabolic profile when there is an adequate level of physical activity.

Obective: The aim of the present paper was to explore how the composition of dietary fat changes across the EU with low- and high-fat diets and to explore levels of physical activity and attitudes to physical activity across the EU.

Design: The paper draws on data contained in reports and supplements of the Institute of European Food Studies in the EU.

Results: There is a clear trend for southern EU states to have higher MUFA intakes and lower SFA intakes than northern EU states. However, for both geographic regions, the fatty acid composition of dietary fat was similar in groups with lower or higher dietary fat intakes. Physical activity was ranked low by consumers $(n=15,000)$ for its importance in relation to health and the prevention of weight-gain. Some $47 \%$ agreed that their present level of physical activity is sufficient. $78 \%$ agreed that being $13 \mathrm{~kg}$ heavier would not be detrimental to health and 30\% agreed that the main benefit of physical activity was to relieve stress.

Conclusions: (i) The present strategy of lowering dietary fat intake does not alter dietary fat composition and (ii) there is a high level of ignorance among consumers of the benefits of physical activity and the adverse effects of excess body-weight.
\end{abstract}

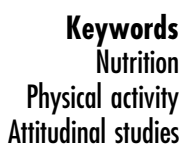

Nutrition Attitudinal studies

\section{Key message}

- At present in all parts of the EU, lower fat diets are associated with the same fatty acid composition as high fat diets. The proposed adverse effects of low fat diets are confounded by a largely sedentary population and the adverse effects can be overcome with modest levels of physical activity. However physical activity is poorly rated by the population for it's health benefits and is not perceived to be beneficial unless it leads to weight loss. Clearly, there is enormous scope for a Pan EU promotion of the benefits of physical activity, independent of weight control.

\section{Introduction}

The purpose of this article is to provide an overview of diet, physical activity and health in Europe. In the context of the present symposium which seeks to examine the interactive effects of diet and physical activity on health, a number of diseases and conditions are being discussed: obesity, diabetes, hyperlipoproteinaemia, hypertension, stroke, osteoporosis, cancer and impaired cognitive function. To begin to document the prevelance and incidence of such conditions and to comment on their rates of change is beyond the scope of a single scientific paper. However, it can be taken as a fact that across Europe, such diseases and conditions significantly contribute to the public health burden. The relative importance of each vary and the rates of change in each also vary. Thus the present paper sets out to examine the variation in diet and physical activity across the European Union (EU).

\section{Dietary variation across the $\mathrm{E} U$}

The European diet is characterized by marked variation in every aspect of eating from the timing of meals to the foods composing those meals. Many studies have compared dietary patterns across the EU using intake data, blood biochemical data or data on biomarkers of 
Table 1 Typical energy and percent distribution of energy in northern and Southern EU member states

\begin{tabular}{|c|c|c|c|c|c|c|}
\hline & \multirow{2}{*}{$\begin{array}{l}\text { Energy } \\
\mathrm{MJ} / \mathrm{d}\end{array}$} & \multicolumn{4}{|c|}{ \% energy } & \multirow[b]{2}{*}{ Reference } \\
\hline & & Carbohydrate & Protein & Fat & Alcohol & \\
\hline \multicolumn{7}{|l|}{ Southern EU } \\
\hline Italy & 8.7 & 48 & 17 & 33 & 3 & 8 \\
\hline Spain & 8.9 & 40 & 20 & 38 & 3 & 9 \\
\hline Greece & 7.6 & 44 & 14 & 40 & 2 & 10 \\
\hline Portugal & 9.7 & 49 & 18 & 29 & 6 & 11 \\
\hline \multicolumn{7}{|l|}{ Northern EU } \\
\hline Finland & 9.0 & 48 & 16 & 34 & 3 & 12 \\
\hline Germany & 9.6 & 39 & 15 & 41 & 4 & 13 \\
\hline Sweden & 8.8 & 46 & 15 & 37 & 2 & 14 \\
\hline Ireland & 9.4 & 48 & 15 & 35 & 2 & 15 \\
\hline
\end{tabular}

nutrient intake ${ }^{1}$. In a symposium that seeks to examine the interaction between diet and physical activity, there is little value in a descriptive comparison of variation in dietary patterns across the EU since many publications already exist on this topic ${ }^{2}$. However, given the quite public debate on the relative wisdom in terms of public health nutrition strategies of, on the one hand reducing total fat intake, particularly saturated fatty acids (SFA) or, on the other hand of maintaining dietary fat levels at their present intakes but replacing SFA with either polyunsaturated ( PUFA) or monounsaturated (MUFA) fatty acids, it would seem wothwhile to explore this issue in terms of variation in the EU diet. This is examined in Table 1 which compares typical northern states for dietary macronutrient composition. Energy intakes are about $9.0 \mathrm{MJ} / \mathrm{d}$ and fat energy ranges from 29 to $40 \%$ in the south to 35 to $41 \%$ in the north. The true north-south divide is seen in Table 2 . In three typical southern countries, the \% energy from SFA ranges from 9 to $13 \%$ which compares with a range of $14-18 \%$ in the north. In contrast, the \% energy from
MUFA is higher in the south (range 12-20) than in the north (range 11-15). The intake of PUFA is similar across Europe. However, when the composition of dietary fat is examined to exclude variation in percent energy from fat i.e. \% wt/wt of dietary fat, it is clear that there is a marked and consistent north-south difference.

Virtually half of the dietary fatty acids in the south are MUFA while in the north, SFA almost approach this. In the context of obesity, the prevailing wisdom is that lower fat diets of $30-35 \%$ fat energy will help prevent the steady rise in weight gain which has been witnessed in some European countries ${ }^{3}$. This argument is countered by others who argue that the dietary fatobesity link is unfounded and, moreover, that low fat diets have adverse metabolic effects such as elevated plasma triacylglycerol (TAG) levels, reduced plasma high-density lipoprotein (HDL) cholesterol and increased peripheral insulin resistance ${ }^{4}$. These effects are certainly observed in some, but not all, studies of low-fat diets. However, they can be countered by an

Table 2 Compositions of dietary fat expressed (a) as a\% of energy and (b) as dietary fatty acid categories as a $\%(w / w)$ of total dietary fatty acids in typical southern and northern EU member states

\begin{tabular}{|c|c|c|c|c|c|}
\hline & Total fat & SFA & MUFA & PUFA & Reference \\
\hline \multicolumn{6}{|c|}{ (a) Dietary fatty acids as a \% of energy } \\
\hline Spain & 38 & 13 & 17 & 5 & 9 \\
\hline Greece & 40 & 12 & 20 & 5 & 10 \\
\hline Portugal & 29 & 9 & 12 & 5 & 11 \\
\hline \multicolumn{6}{|l|}{ Northern } \\
\hline Finland & 34 & 14 & 11 & 5 & 12 \\
\hline Germany & 41 & 18 & 15 & 6 & 13 \\
\hline Netherlands & 38 & 15 & 14 & 7 & 16 \\
\hline \multicolumn{6}{|c|}{ (b) Dietary fatty acids as a \% of dietary fatty acids } \\
\hline Spain & 100 & 37 & 49 & 14 & 9 \\
\hline Greece & 100 & 32 & 54 & 14 & 10 \\
\hline Portugal & 100 & 35 & 46 & 19 & 11 \\
\hline \multicolumn{6}{|l|}{ Northern } \\
\hline Finland & 100 & 47 & 37 & 16 & 12 \\
\hline Germany & 100 & 46 & 38 & 15 & 13 \\
\hline Netherlands & 100 & 42 & 39 & 19 & 16 \\
\hline
\end{tabular}


adequate intake of n-3 PUFA which will lower plasma $\mathrm{TAG}^{5}$ and by exercise which will raise HDL cholesterol and will improve insulin function ${ }^{6}$.

Lower fat diets are unquestionably associated with lower intakes of SFA but as can be seen in Table 3a, there are also reductions in MUFA and PUFA on lower fat diets. When the composition of dietary fat is considered, (Table 3b), it is clear that lower fat diets have the same fatty acid composition as higher fat diets in both the north and south of Europe. People who choose a lower-fat diet simply eat less of the same balance of fats. If those who advocate a lower SFA, higher MUFA diet wish to attain their objectives, then they must seek to alter the fatty acid composition of many foods which will pose a difficult technological problem. It is evident that the foods which make up the fat portion of low- and high-fat diets are the same. Otherwise the fatty acid compositions would be different. Since in northern EU states, most SFA comes from dairy produce, meat and meat products, eggs and egg dishes and the like, it is difficult to see how the fatty acid composition of these products could be altered. If a reduced intake of these foods is associated with a simultaneous lowering of MUFA or PUFA, then candidate foods for enrichment in MUFA and PUFA will have to be found if the idea is to lower saturates but to keep fat levels constant by replacing displaced SFA with PUFA and MUFA and that is technologically difficult. Only a major shift in food selection would achieve this desired objective. The cultural barriers to that are considerable. The more sensible option would be to promote low-fat diets in the context of broader dietary advice to increase oily fish, rich in n-3 PUFA, and to promote moderate physical activity, both of which will negate the proposed adverse health effects of a low fat diet.

\section{Physical activity and attitudes to physical activity across the EU}

In the development of a public health nutrition programme to promote physical activity, it is necessary to understand consumer attitudes to physical activity. This was done recently in a study which ascertained the attitudes of 1000 adults in each EU member state to physical activity, bodyweight and health ${ }^{7}$ and the key findings are as follows.

(i) In terms of factors perceived to be most important for health, body-weight was cited by only $9 \%$ as being one of the two most important factors. This contrasts with the \% citing smoking (41\%), food (38\%), stress (33\%), alcohol intake (20\%), physical activity (18\%) and the environment (16\%).

(ii) In terms of the two most important factors for preventing weight gain, physical activity (17\%) ranked below food (44\%), fat (39\%), sugar (22\%) and genetics (18\%).

(iii) $78 \%$ agreed with the statement "Being $13 \mathrm{~kg}$ heavier than I am would be detrimental to my health" and $47 \%$ agreed with the statement "I do not need to do more physical activity than I already do".

(iv) Among the perceived motivating factors for participation in physical activity/exercise, "to maintain good health" was highest (42\%) followed by "to release tension" (30\%), "to get fit" (30\%), "to be out of doors" (20\%), "to socialise" (14\%) and "to control weight" (13\%).

Table 3 Dietary fat composition expressed as (a) a \% of energy or (b) as dietary fatty acid categories as a \% $(\mathrm{w} / \mathrm{w})$ in upper and lower quartiles/tertiles of \% energy from fat in typical southern and northern EU states

\begin{tabular}{|c|c|c|c|c|c|c|}
\hline & \multicolumn{3}{|c|}{ Low-fat diets } & \multicolumn{3}{|c|}{ High-fat diets } \\
\hline & SFA & MUFA & $\begin{array}{l}\text { PUFA } \\
\text { PUA }\end{array}$ & SFA & MUFA & $\overline{\text { PUFA }}$ \\
\hline \multicolumn{7}{|c|}{ (a) dietary fatty acids as a \% of energy } \\
\hline Spain & 11 & 15 & 4 & 14 & 19 & 9 \\
\hline Greece & 8 & 12 & 4 & 15 & 28 & 10 \\
\hline Portugal & 6 & 10 & 4 & 11 & 15 & 11 \\
\hline \multicolumn{7}{|l|}{ Northern } \\
\hline Finland & 11 & 8 & 4 & 18 & 14 & 12 \\
\hline Germany & 14 & 12 & 5 & 21 & 17 & 13 \\
\hline Netherlands & 12 & 11 & 5 & 17 & 17 & 16 \\
\hline \multicolumn{7}{|c|}{ (b) dietary fatty acids as a $\%$ of dietary fatty acids } \\
\hline \multicolumn{7}{|c|}{ Southern } \\
\hline Spain & 37 & 50 & 13 & 37 & 50 & 9 \\
\hline Greece & 34 & 51 & 15 & 30 & 50 & 10 \\
\hline Portugal & 32 & 48 & 20 & 35 & 47 & 11 \\
\hline \multicolumn{7}{|l|}{ Northern } \\
\hline Finland & 47 & 37 & 17 & 48 & 38 & 12 \\
\hline Germany & 45 & 40 & 15 & 46 & 39 & 13 \\
\hline Netherlands & 41 & 39 & 19 & 40 & 40 & 16 \\
\hline
\end{tabular}


Table 4 BMI categories (\%), active: inactive hours, weight change and attitude to weight-loss benefits of physical activity from a survey of $15,000 \mathrm{EU}$ adults $^{7}$

\begin{tabular}{|c|c|c|c|c|}
\hline & Under-weight & Normal-weight & Over-weight & Obese \\
\hline BMI $\left(\mathrm{kg} / \mathrm{m}^{2}\right)$ & $<20$ & $>20-25$ & $>25-30$ & $>30$ \\
\hline$\%$ of subjects & 11 & 48 & 31 & 10 \\
\hline (EU range) & $(8-17)$ & $(46-53)$ & $(24-35)$ & $(7-12)$ \\
\hline \multicolumn{5}{|l|}{ Ratio of hours } \\
\hline \multicolumn{5}{|l|}{ Active : inactive } \\
\hline Week-end & $1: 0.9$ & $1: 1.1$ & $1: 1.4$ & $1: 1.20$ \\
\hline Week-day & $1: 1.6$ & $1: 2.1$ & $1: 2.9$ & $1: 4.4$ \\
\hline \multicolumn{5}{|c|}{ Weight change in recent 6 months } \\
\hline$\%$ gaining & 13 & 19 & 27 & 31 \\
\hline$\%$ losing & 19 & 13 & 16 & 20 \\
\hline$\%$ no change & 66 & 66 & 57 & 47 \\
\hline \multicolumn{5}{|l|}{ Statement } \\
\hline \multicolumn{5}{|c|}{ "unless physical activity / exercise results in weight loss, I am not really benefiting" } \\
\hline$\%$ agreeing & 22 & 23 & 28 & 32 \\
\hline$\%$ disagreeing & 74 & 72 & 65 & 59 \\
\hline
\end{tabular}

These data highlight the level of antipathy toward exercise and physical activity, a belief that present levels of sedentary behaviour are acceptable, and they also highlight the widespread ignorance of the adverse effects of over-weight and obesity. The scale of the problem is shown in Table 4 where $31 \%$ of EU subjects are over-weight and $10 \%$ are obese, the table also shows that inactivity is a stronger feature among the over-weight and obese and that there is a high percentage of the population who are gaining or losing weight. Perhaps the most worrying data in this table is that about $20-30 \%$ of subjects (increasing with increasing BMI) agree that unless physical activity brings weight loss, there is no personal benefit. The strategy recommendations of the study were as follows.

(i) "Increase awareness of the health benefits of physical activity irrespective of body-weight"

It is evident from the study that there is a high level of ignorance about both the adverse effects of obesity and overweight and the health benefits of exercise. In terms of factors that are important for health, physical activity is ranked below stress and in terms of factors influencing weight gain, physical activity is ranked below genetics. The study suggests the possibility of decoupling the health benefits of physical activity from the issue of obesity.

(ii) "Increase awareness that physical activity means all sorts of activities such as gardening, walking, dancing, golf, football etc and not just "sport".

This means conveying the message that most of the health benefits of physical activity are gained by moving from a sedentary lifestyle to one with a moderate level of daily physical activity".

One in three people are not engaged in any voluntary physical activity and one in four excuse this because they are not the "sporty type". There is a need to stress that the health benefits of physical activity can accrue from such everyday activities as walking or gardening since the two biggest barriers to engaging in physical activity were not having enough time and not being the sporty type.

(iii) "Promote the concept of physical activity to relieve stress and increase awareness among employers and trade unions that the work/study environment should promote and facilitate increased physical activity".

Stress was selected by one third of the EU subjects as an important influence on health. Relief of stress was also seen as an important motivating factor for taking part in physical activity. These surprising results suggest that stress management should be one basis for promoting physical activity. Since work/study commitments are major sources of stress in most people's lives, the relief of that stress in a caring work environment which facilitates exercise would seem not unreasonable.

(iv) "Ensure that health professionals understand the benefits of physical activity and have access to appropriate advice to promote increased physical activity and provide quantitative advice on options for increasing physical activity targeted at specific sub-groups on the population".

The results of the survey show that $75 \%$ of the population believe that health professionals are good sources of information on the health benefits of physical activity. Moreover this is consistent across all member states which would suggest that a Pan EU campaign to involve and inform health professionals would be a possible option.

\section{Conclusions}

At present in all parts of the EU, lower fat diets are associated with the same fatty acid composition as high 
fat diets. The proposed adverse effects of low fat diets are confounded by a largely sedentary population and the adverse effects can be overcome with modest levels of physical activity. However physical activity is poorly rated by the population for it's health benefits and is not perceived to be beneficial unless it leads to weight loss. Clearly, there is enormous scope for a Pan EU promotion of the benefits of physical activity, independent of weight control.

\section{References}

1 Schroll K, Moreiras-Varela O, Schlettwrin-Gsell D, Decarli B, de Groot L, van Staveren W. Cross cultural variations and changes in food-group intake among elderly women in Europe: Results from the survey in Europe on Nutrition and the Elderly-a concerted action (SENECA). A. J. Clin. Nutr. 1997; 65: 1282-95.

2 Winkler G, Doring A, Keil U et al. Comparisons of dietary intakes in four elected European Countries. Clin. Invest. 1992; 70: 889-95.

3 Gibney MJ. Epidemiology of obesity in relation to nutrient intake. Int. J. Obesity 1995; 19 (suppl 5): S1-S3.

4 Katan MB, Grundy SM, Willet WL. Beyond low-fat diets. $N$. Eng. J. Med 1997; 334: 1491-9.

5 Roche HM, Gibney MJ. Postprandial triacylglycerolaemia: the effect of low-fat dietary treatment with and without fish oil supplementation. Eur. J. Clin. Nutr. 1996; 50: 617-24.

6 Malkova D, Hardman AE, Bowness RJ, Macdonald IA. The reduction in postrandial lipemia after exercise is independent of the relative contributions of fat and carbohydrate to energy metabolism during exercise. Netavikusn 1999; 48: 245-51.

7 Institute of European Food Studies. A pan-EU survey on consumer attitudes to physical activity, body-weight and health. Luxembourg: Office for Official Publications of the European Communities, 1999.

8 Turrini A, Leclercq C, D'Amicis A. Patterns of food and nutrient intakes in Italy and their application to the development of food-based dietary guidelines. $\mathrm{Br}$. J. Nutr. 1991; 81: S83-9.

9 Serra-Majem L, Ribas L, Ramon JM. Compliance with dietary guidelines in the Spanish population. Results from the Catalan Nutrition Survey. Br. J. Nutr. 1999; 81: S105-12.

10 Moschandreas J, Kafatos A. Food and nutrient intakes of Greek (Cretan) adults. Recent data for food-based dietary guidelines in Greece. Br.J. Nutr. 1999; 81: S71-6.

11 Graca P. Dietary guidelines and food nutrient intakes in Portugal. Br. J. Nutr. 1999; 81: S99-103.

12 Valsta L. Food-based dietary guidelines for Finland- a staged approach. Br. J. Nutr. 1999; 81: S49-55.

13 Hermann-Kunz E, Thamm M. Dietary recommendations and prevailing food and nutrient intakes in Germany. Br.J. Nutr. 1999; 81: S61-9.

14 Becker W. Dietary guidelines and patterns of food and nutrient intake in Sweden. Br. J. Nutr. 1999; 81: S113-7.

15 Flynn MAT, Kearney JM. An approach to the development of food-based dietary guidelines for Ireland. Br. J. Nutr. 1999; 81: S77-82.

16 Lowik MRH, Hulshof KFAM, Brussard JM. Patterns of food and nutrient intakes of Dutch Adults according to intakes of total fat, saturated fatty acids, dietary fibre and of fruit and vegetables. Br. J. Nutr. 1999; 81: S91-8. 